\title{
Nacionalismos, identidades y narraciones ${ }^{1}$
}

\section{Nationalisms, identities and narrative}

Recibido: 28 de octubre de 2014 - Revisado: 13 de febrero 2015 - Aceptado: 2 de marzo de 2015

\section{Claudia Patricia Fonnegra Osorio ${ }^{2}$}

\section{Resumen}

Desde una perspectiva crítica, en este artículo se analizan diferentes interpretaciones del concepto de nación, dando cuenta de los peligros que entraña su defensa radical; posteriormente se da paso a la comprensión del nacionalismo desde un enfoque posmoderno, el cual servirá de guía para el entendimiento de nuevas formas de concebir proyectos identitarios nacionalistas en Colombia.

\section{Palabras clave}

Nación, nacionalismos, Estado, identidades, narraciones.

\begin{abstract}
From a critical perspective, in this article different interpretations of the concept of nation are analyzed, highlighting the dangers of its radical defense; then it gives way to the understanding of nationalism from a postmodern approach, which will be a guide to understand new ways of conceiving nationalistic identity projects in Colombia.
\end{abstract}

\section{Keywords}

Nation, nationalisms, State, identities, narrative.

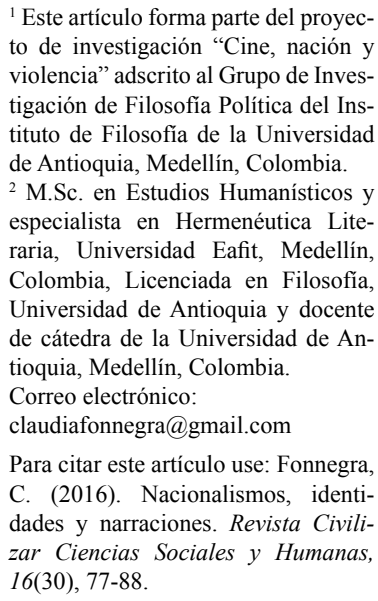

${ }^{1}$ Este artículo forma parte del proyecto de investigación "Cine, nación y violencia" adscrito al Grupo de Investigación de Filosofía Política del Instituto de Filosofía de la Universidad de Antioquia, Medellín, Colombia.

${ }^{2}$ M.Sc. en Estudios Humanísticos y especialista en Hermenéutica Literaria, Universidad Eafit, Medellín, Colombia, Licenciada en Filosofía, Universidad de Antioquia y docente de cátedra de la Universidad de Antioquia, Medellín, Colombia. Correo electrónico:

claudiafonnegra@gmail.com

Para citar este artículo use: Fonnegra, C. (2016). Nacionalismos, identidades y narraciones. Revista Civilizar Ciencias Sociales y Humanas, 16(30), 77-88. 
Somos el invento de quienes nos han narrado: somos la creación de Homero y del Bhagavad Gita, de Cervantes y Shakespeare y Ornar Khayyam. Estos relatos nos susurran al oido quiénes somos. Estos relatos nos recuerdan dónde hemos resbalado. Estos relatos nos permiten reducir la distancia infranqueable y cruel que nos separa de lo que fuimos, y son por eso el único anuncio de lo que podemos ser.

Vásquez (1973)

\section{Introducción}

El nacionalismo se ha definido como ideología o principio de cohesión social que posibilita, después del proceso de secularización, dar lugar al mantenimiento de formas de vida comunitarias. Gracias a él ha sido viable la construcción de lazos de solidaridad que han permitido la configuración de identidades colectivas más o menos estables; pero también, en su nombre, se erigen fundamentalismos que llevan a la negación de la diferencia cultural, al exterminio del extraño, a la satanización del diferente. ¿Es posible continuar afirmando en las sociedades contemporáneas la existencia de proyectos identitarios nacionalistas?, si esto es así ¿cuáles son sus alcances y sus limitaciones?

En este artículo se realizará un recorrido por distintos significados del concepto de nación; se expondrán los peligros que entraña la defensa radical del nacionalismo; se presentará cómo se ha resemantizado este término en la posmodernidad y, por último, se analizarán algunas reflexiones acerca del nacionalismo en Colombia.

\section{Una aproximación al concepto de nación}

El concepto 'nación' posee diferentes acepciones, es polémico y no puede abarcarse en una sola definición ${ }^{1}$. Por ejemplo, desde una perspectiva moderna se habla de nación política, nación cultural o, incluso, se han elaborado síntesis de ambas posturas. La nación política es la agrupación consciente de hombres libres que se autodeterminan y que deciden configurar por voluntad propia una forma de vida colectiva. Con- forme con los ideales de la Ilustración del siglo XVIII, esta manera de concebir la nación parte de la concepción del hombre como ser racional, perfectible, autónomo, quien puede decidir por sí mismo cómo orientar su vida y cómo establecer a partir del diálogo pactos sólidos para dirigir de modo mancomunado proyectos sociales.

Desde este punto de vista la nación requiere de la existencia de un conjunto de instituciones estatales que permita canalizar los conflictos sociales a través de vías democráticas. Esta visión ilustrada fundada por autores como Rousseau y Montesquieu, se basa en la construcción de una ciudadanía que confiere a los hombres el estatuto de personas portadoras de igualdad de derechos y deberes ante la ley.

Eric Hobsbawm (2000) asegura que en la Europa de la era de las revoluciones, prima la defensa de un nacionalismo que se apoya en los valores de la Revolución francesa: igualdad, fraternidad y libertad. Así que, una nación no requiere estar enmarcada por la existencia de elementos prepolíticos de carácter étnico, "el significado primario de nación, el significado que con mayor frecuencia se aireaba en la literatura, era político" (p. 27). Así la nación se presenta como una creación y conquista moderna racionalmente deliberada ${ }^{2}$.

La nación cultural, por su parte, alude a la defensa de la configuración de la identidad de un pueblo que se fundamenta en principios étnicos, en la herencia de una tradición, en su lengua, en sus símbolos, mitos y ritos. Esta definición del nacionalismo tiene su origen en el movimiento romántico de finales del siglo XVIII, el cual se instituye en contra de principios "artificiales" y "abstractos" propios de un cientificismo racionalista que elimina las características autóctonas de un pueblo. Por ejemplo en el texto de Herder Ideas para una filosofia de la historia de la humanidad que se publicó entre los años 1784 y 1791, se asegura que la vida en sociedad se edifica a partir de las condiciones climáticas y territoriales, las cuales 
configuran un ethos particular que diferencia a un grupo humano de otro, para el autor

[...] verdad es que somos arcilla moldeable en manos del clima, cuyas manos empero saben moldear de manera tan variada que tal vez solo un gran genio del género humano sería capaz de resolver la proporción de todas estas fuerzas en una ecuación (Herder, 17841791/2000, p. 38).

Otro representante de la defensa de la nación cultural es Fichte (1998). En Discurso a la nación alemana publicado entre 1807 y 1808, el autor asegura que no es en el seguimiento de principios jurídicos donde reside la fuerza de la organización de un Estado, "en el mantenimiento de la constitución heredada de las leyes, del bienestar del ciudadano, no hay una vida verdaderamente auténtica ni una decisión originaria" (p. 144), lo que une entonces a una comunidad, lo que hace posible su mantenimiento y defensa son sus lazos culturales, "la llama ardiente del amor superior a la patria que entiende la nación como envolvente de lo eterno" (p.145), de suerte que es en estos principios espirituales donde se encuentra la posibilidad de que un pueblo adquiera conciencia de sí y reconozca a un gobierno como suyo ${ }^{3}$.

En el siglo XIX, Ernest Renan (2000) en la célebre conferencia “¿Qué es una nación?” de 1882 sostiene que la nación requiere, en primer lugar, de una historia común con la que un pueblo se identifique creando lazos de solidaridad.

La nación, como el individuo, es la desembocadura de un largo pasado de esfuerzos, de sacrificios y de abnegaciones. El culto de los antepasados es el más legítimo de todos; los antepasados nos han hecho lo que somos. Un pasado heroico, grandes hombres, gloria -entiéndase verdadera gloria-; he aquí el capital social sobre el que se asienta una idea nacional (p. 65).

Se aclara que para el autor una nación no se asienta en tradiciones dinásticas, en elementos raciales, lingüísticos, religiosos o territoriales, pero sí requiere de una tradición histórica que permita la creación de lazos afectivos que unan un pueblo. Para el escritor en cita, la nación urge de un principio "voluntarista" que legitime la unidad de una comunidad, se trata de un principio claramente político que le da validez a la organización social establecida.

La existencia de una nación es (perdónenme esta metáfora) un plebiscito de todos los días, como la existencia de un individuo es una afirmación perpetua de la vida [...]. Una nación no tiene jamás el verdadero interés en anexionarse o en retener un país en contra de su voluntad. El voto en las naciones es, en definitiva, el único criterio legítimo, aquel al que es necesario volver (p. 65).

Desde esta perspectiva la nación es una síntesis de elementos culturales y principios políticos ${ }^{4}$.

Una nación es un alma, un principio espiritual. Dos cosas que tan solo hacen una, constituyen esta alma o principio espiritual. Una está en el pasado, otra en el presente. Una es la posesión en común de un rico legado de recuerdos; otra es el consentimiento actual, el deseo de vivir juntos, la voluntad de seguir haciendo valer la herencia que se ha recibido indivisa (Renan, 2000, p. 65).

Ahora bien, sobre la base de las anteriores definiciones de nación (política, cultural o síntesis de ambas perspectivas) se han gestado diversos proyectos que sirven al proceso de cohesión del Estado de derecho moderno, el cual se concibe como institución soberana, encargada de regular el orden social a través de marcos legales y de la pretensión del monopolio de la fuerza física legítima ${ }^{5}$.

\section{El Estado nación como principio de} homogeneización cultural y política

Hannah Arendt (1993) en su texto $L a$ condición humana de 1958 expone que en la modernidad se da el triunfo de la esfera de lo 
social y, sobre esta, se alza la consolidación de los Estados nacionales. Para la escritora, en la antigüedad clásica griega se daba claramente una distinción entre el ámbito de las relaciones privadas y el ámbito de lo público. El primero se concebía como espacio de privación, allí los hombres carecían de la posibilidad de hablar y de discutir entre pares sobre asuntos comunes; no obstante, lo privado también tenía un valor positivo fundamental, ya que se entendía como un espacio de protección, de ocultamiento, el cual resultaba necesario para llevar a cabo labores domésticas, suplir las necesidades básicas, crear obras de arte, producir pensamiento, amar...

El ámbito de lo público se concebía como lugar luminoso, en el que los hombres aparecían ante otros expresando sus visiones del mundo, mostrando su identidad, posibilitando consensos, realizando acciones conjuntas.

Arendt (1993) señala que societas es un término latino que surge para designar la reunión de los hombres alrededor de un único propósito. Este dio paso a la aparición de un nuevo espacio en el que lo que tradicionalmente se pensaba como privado comenzó a tornarse público. Según Arendt, dicho espacio adquiere gran fuerza en la modernidad, ya que sobre la base de lo social tiene lugar el surgimiento del Estado nacional, el cual se concibe como una gran familia que, apoyada en necesidades idénticas, reúne a los hombres. Así, el Estado nacional debe velar por el mantenimiento de los intereses de individuos atomizados que han sacrificado la existencia de un espacio para el encuentro intersubjetivo, en favor de la protección de la propiedad, de la economía o de visiones particulares del mundo:

A este respecto no es de gran importancia que una nación esté formada por iguales o desiguales, ya que la sociedad siempre exige que sus miembros actúen como si fueran miembros de una enorme familia con una sola opinión e interés (p. 50).
El auge de lo social, el advenimiento de la sociedad de masas y el arribo de la estadística (técnica para medir las tendencias del comportamiento de los sujetos), son para Arendt resultado de la sustitución de la acción libre por la estandarización de conductas propias de intereses nacionales particularistas.

En el importante libro Los orígenes del totalitarismo, Arendt (1974) sostiene que el Estado moderno se construye en medio de paradojas: por un lado está la promulgación universal de derechos humanos que busca eliminar los privilegios estatutarios de ciertos grupos sociales, pero por otro está la consolidación de poderes hegemónicos que se cimientan en valores culturales unívocos, que no admiten las disidencias:

Nacionalismo significa la conquista del Estado por una nación. Tal es el sentido del Estado nacional. El resultado de la identificación decimonónica entre nación y Estado es doble: mientras que el Estado como institución legal asumía como su deber proteger los derechos de los hombres, su identificación con la nación implicaba la identificación del ciudadano con el nacional, de lo que resultaba una confusión de derechos del hombre con los derechos de los nacionales (p. 257).

Confundir derechos humanos con derechos nacionales permite dejar de lado la protección jurídica de los ciudadanos, para darle paso a la defensa de una visión particular de lo que debe ser "la naturaleza humana", lo cual va en detrimento de otras "maneras de ser hombre". En la misma línea argumentativa, el investigador Alfredo Cruz Prados (2005) comprende la construcción del Estado nacional como un proceso que exalta elementos identitarios prepolíticos.

Ante el fenómeno de disgregación social causada por la reforma protestante, el nacionalismo facilitó el establecimiento un nuevo principio por el que los integrantes de una comunidad estaban dispuestos a obedecer las normas y 
a mantener el orden. El Estado nacional idealizó la patria, creo principios de solidaridad entre familias y entre estas y las instituciones que las regulaban:

El nacionalismo necesita hacer de su proyecto el único que verdaderamente responde a la realidad de la nación; el único que es asignable a esta como su proyecto propio y exclusivo: el único proyecto político que posee, por tanto, legitimidad nacional. Afirmar la nación, y afirmarse como miembro de ella, implica directa e inmediatamente adherirse al único proyecto político que es realmente un proyecto para la nación y de la nación. Existe una perfecta equivalencia, una absoluta identidad, entre hacer propia la nación y hacer propio su proyecto político: el proyecto político nacionalista.

Quienes, en el marco de la nación, optan por un proyecto distinto del nacionalista no son calificados solamente con términos que -por decirlo así- pertenecen al debate político ordinario y doméstico: "derecha", "izquierda", "socialista", "liberal", etc. La oposición y la adhesión al proyecto nacionalista hacen al sujeto merecedor de una calificación -o descalificación- mucho más radical y comprehensiva: "traidor" o "patriota", "vosotros" o "nosotros" [...]. La valoración de estas posturas se lleva a cabo en términos de identificación o enajenación con la comunidad nacional, de fidelidad o infidelidad a ella (Cruz-Prados, 2005, pp. 122-123).

De cara a lo anterior, Cruz Prados no vacila en hablar de la crisis del nacionalismo, ideología que si bien puede crear la estabilidad política de un Estado, símbolos y narrativas que lo cohesionen, también puede conducir, cuando es asumido de manera radical, a la negación del pluralismo y a guerras totalitarias. Por tanto el autor asegura:

La proliferación, en los años treinta y cuarenta, de dictaduras y regímenes autoritarios acabó de poner de manifiesto el fracaso del principio de nacionalidad como instrumento de armonía y pacificación. Se hizo patente que, en momentos difíciles o de crisis la apelación a la nación, a unos pretendidos intereses puramente "nacionales", situados por encima del mero debate entre partidos políticos, puede servir para poner fin al espíritu y a la práctica de la democracia y abrir las puertas al autoritarismo de un poder salvador y "nacional" (p. 138).

De ahí que se planteara como necesario revisar las bases sobre las que se construyeron los proyectos nacionalistas modernos ${ }^{6}$.

\section{La nación desde una perspectiva posmoderna $^{7}$}

¿Cómo leer en la contemporaneidad la existencia de proyectos nacionalistas? ¿Conducen estos necesariamente al planteamiento de políticas de exclusión y a nuevas formas de totalitarismos? O, por el contrario, ¿pueden contribuir positivamente a la creación de una imagen colectiva en la que allende a las diferencias se conformen principios identitarios?

Néstor García Canclini (1989) asegura que para evitar el auge de regímenes políticos conservadores, ortodoxos y autoritarios la cultura debe someterse a escrutinio crítico, a evaluación permanente, a la configuración de miradas diversas, a la apertura del devenir del cambio. Esto supone dejar a un lado la creencia en la existencia de identidades puras, estables, auténticas. Aquí está en juego la posibilidad de mirar el pasado a partir de las preguntas que se formulan desde el presente. Un presente en proceso de hibridación, es decir, compuesto de comunidades mestizas, de tradiciones diversas y cambiantes en las que se entremezcla lo culto con lo popular, lo premoderno con lo posmoderno, lo rural con lo urbano, lo local con lo cosmopolita. Para García Canclini (2003):

Los estudios sobre narrativas identitarias hechos desde enfoques teóricos que toman en cuenta los procesos de hibridación (Hannerz, Hall) muestran que no es posible hablar de las identidades como si sólo se tratara de un 
conjunto de rasgos fijos, ni afirmarlas como la esencia de una etnia o una nación (p. 6).

Por tanto, es necesario deconstruir los discursos que operaban como libretos que identificaban y prescribían el deber ser de una comunidad:

La desaparición del libreto quiere decir que ya no existen los grandes relatos que ordenaban y jerarquizaban los periodos del patrimonio, la vegetación de obras cultas y populares en las que las sociedades y las clases se reconocían y consagraban sus virtudes (García-Canclini, 1989, p. 307).

Sin embargo, lo anterior no significa que dejen de operar narraciones que dan lugar a la configuración de un ethos comunitario. "Algunos entendemos que la caída de los relatos totalizadores no elimina la búsqueda crítica de sentido -mejor de sentidos- en la articulación de las tradiciones y la modernidad" (p. 307).

¿Pero cómo construir estos nuevos sentidos? Es claro que no se trata de afirmar un relato nacional único, una mirada monista de él, pues tal y como asegura Gianni Vattimo (1994) "No existe una historia única, existen imágenes del pasado propuestas desde diversos puntos de vista, y es ilusorio pensar que exista un punto de vista supremo, comprehensivo, capaz de unificar todos los demás" (p. 11). Se trata, entonces, de dar lugar a la diversidad de múltiples manifestaciones culturales, desde la alteridad que posibilita la afirmación de sí mismo.

Anthony Smith (2003) plantea que las sociedades en las que han imperado prácticas políticas negadoras de un espacio público en el que la pluralidad de voces tenga lugar, han pensado la nación desde un enfoque posmoderno ${ }^{8}$. Este enfoque retoma el concepto de comunidad imaginada de Benedict Anderson (1993), para presentar la nación como el conjunto de símbolos, relatos, tradiciones, obras artísticas... con el cual se proyecta un modelo de comunidad viva que nutre y se nutre de tradiciones diversas y cambiantes. De modo que la nación, más que un principio real da cuenta de un mundo por inventar:

Construir la nación es más una cuestión de diseminar representaciones simbólicas que de forjar instituciones culturales o redes sociales. Aprehendemos los significados de la nación a través de las imágenes que proyecta, los símbolos que usa y las ficciones que evoca en novelas, obras de teatro, poemas, óperas, baladas, panfletos y periódicos que un público lector alfabetizado devora ávidamente. Es en estas creaciones simbólicas y artísticas donde podemos discernir los rasgos de una nación (Smith, 2003, p. 13).

Así que, conforme con este enfoque posmoderno, la nación es una invención, pero en lugar de crearse desde un dispositivo de poder propio de los Estados capitalistas modernos, se crea y recrea desde distintas narrativas en las que múltiples actores sociales tienen lugar.

\section{Colombia: Estado, violencia y nación}

La configuración del Estado colombiano ha estado marcada por la lógica de la guerra, la violencia y la exclusión social. Para comprender esta tesis resulta útil acudir a María Teresa Uribe (2001), para quien "en Colombia la guerra y la violencia han sido ejes estructurantes y vertebradores del Estado nacional o de lo que tenemos por tal" (p. 250). Esto es así porque desde la época republicana hasta nuestros días ha primado el disenso en torno a qué principios políticos seguir para gobernar en un territorio geográficamente vasto, con profundas desigualdades sociales y con culturas híbridas. Desde las antiguas querellas en torno a la configuración de un Estado federalista o centralista, pasando por las disputas bipartidistas y por la creación de grupos insurgentes y contrainsurgentes, el Estado colombiano se ha caracterizado por su fragmentación.

No se puede hablar en Colombia de la existencia de una homogeneidad étnica y cultural 
que posibilite aglutinar en los mismos referentes identitarios la diversidad de regiones del país. De ahí que en el afianzamiento de un proyecto de Estado cohesionado resultara imposible apelar a la defensa de un nacionalismo como el defendido por el movimiento romántico. Por otra parte, desde la fundación de la República se dieron múltiples discusiones y guerras en torno a cómo concebir la nación, lo cual impidió consolidar un ideal político unificado ${ }^{9}$.

María Teresa Uribe (2001) señala que en Colombia no se ha dado una guerra abierta y continua en el tiempo, también reconoce que son varios los actores que han fomentado la violencia en nuestro país. Pese a que plantea la existencia de un conflicto armado de larga duración que se ha manifestado en periodos bélicos de alta y baja intensidad, para la autora, el conflicto armado colombiano puede estudiarse conforme con el concepto de "Estados de guerra", el cual se define como una situación de hostilidad latente entre diversos grupos políticos que no desean someterse al poder del Estado; en este contexto, la presencia de una constante voluntad de combate animus belli, dificulta la formación de una conciencia nacional homogénea.

El conflicto armado es un eje de larga duración que atraviesa la historia de la nación colombiana. Sin embargo, esto no significa, necesariamente, una confrontación continua, permanente y generalizada; una guerra abierta y sin pausa entre hostiles con su caudal de muertes, destrucción y sangre derramada. La naturaleza de nuestro conflicto armado se enmarca de mejor manera en un viejo concepto hobbesiano retomado por Foucault: los Estados de guerra. Para estos autores, los Estados de guerra son situaciones en las cuales el poder institucional no es soberano, por lo menos en algunas partes del territorio y entre sectores amplios de la colectividad nacional en los cuales prevalece la voluntad manifiesta de no someterse al orden estatal y de resistir a sus intentos de establecer dominio y control, manteniendo abierta la posibilidad de confrontarlo y de combatirlo con las armas en la mano, así como de agrupar a los sujetos sociales de su entorno en bandos capaces de matar y de mo$\operatorname{rir}($ p. 251).

De lo anterior se deriva la inexistencia de una esfera público-política en la que el discurso y la acción se constituyan como pilares para la construcción de proyectos colectivos basados en el reconocimiento de la pluralidad humana, además de la ausencia de símbolos culturales estables y duraderos que cobijen a todo el corpus de la nación. Ahora bien, la autora no niega la incidencia del poder del Estado ni de sus instituciones en lo que denomina "la sociedad mayor”, pero sí presenta su inoperancia en zonas periféricas, aquellas en donde se establecen las territorialidades bélicas o los órdenes alternativos anteriormente señalados. Por ello afirma que:

Colombia tiene una especie de columna vertebral conformada por territorios incluidos en los que se llama el centro del país; allí se asienta el poder institucional y funcionan mal que bien los referentes simbólicos, las formas de representación, las identidades colectivas; en suma esta es la base de la sustentación del poder. El resto está por fuera de su control y son otros los procesos que se tejen y destejen, otros los agentes del poder, otros los mecanismos de dominación, otras las identidades, otros los sentidos de pertenencia [...] otros los países (p. 26).

Para María Teresa Uribe en Colombia las identidades comunitarias se han construido desde situaciones coyunturales diversas y cambiantes: compartir vínculos de resistencia social, buscar colectivamente protección y seguridad privada, crear alianzas a partir de las lógicas impuestas por los conflictos bélicos, etc., pero la autora sostiene que

[...] las identidades que se configuran en el crisol de las guerras son frágiles y adjetivas, no solo por la heterogeneidad social y cultural de los pobladores sino, ante todo, porque estas saben por la propia experiencia y los viejos relatos familiares, que todo dominio es frágil, 
vulnerable y en permanente disputa, y que la protección otorgada por unos u otros puede desaparecer en los avatares del conflicto (p. 267).

De ahí que la guerra en Colombia ha impedido pensar la nación desde unos referentes estables. Cercano a este tema Martín Barbero (2005) escribe:

Si en Colombia hay una cuestión de fondo, que este país tiene aún pendiente -irresuelta tanto en el pensamiento como en la acción-, es la muy especial relación entre política y violencia en la trama de sus memorias y de su historia (párr. 2).

Es entonces necesario reinterpretar nuestro pasado e inventar la dirección de nuestro futuro, tal como se presenta en un enfoque posmoderno del nacionalismo.

\section{A modo de conclusión}

En este texto se buscó mostrar algunas interpretaciones del concepto de nación y exponer los problemas presentes en la defensa radical de proyectos nacionalistas modernos. Se reivindicó una perspectiva posmoderna que encuentra en el reconocimiento del pluralismo la posibilidad de la "construcción" de nuevos relatos nacionales más inclusivos. Para el caso de Colombia, esta lectura guarda gran riqueza, ya que aquí está en juego la apuesta por reconstruir la nación a partir de la recuperación y comprensión de su pasado histórico: doloroso, convulsivo, violento, marcado por el desarraigo, la pobreza, la guerra y el olvido propio de un Estado de guerra en el que múltiples actores sociales ejercen pretensiones soberanas, bien sea por la vía de la fuerza o del consenso; pero aquí también se trata de la posibilidad de crear la nación, de soñarla a partir de la polifonía de las narraciones de múltiples actores sociales que solo pueden tejer identidades híbridas, necesarias para un nuevo reconocimiento de la colombianidad.

A propósito, William Ospina (2001) asevera que nuestra historia está atravesada por la violencia y esta, en lugar de negarse, debe comprenderse, para ello despliega un bello símil construido a partir de una imagen literaria presente en Cien años de soledad: así como Úrsula Iguarán persiguió la huella de sangre que la llevaría al cuerpo sin vida de su hijo José Arcadio Buendía, los ciudadanos de hoy deben rastrear las huellas de la sangre derramada en sus pueblos. Así que, para comprender la complejidad de las crisis que atraviesa Colombia es menester explorar su pasado, pero no se trata de acudir únicamente a los archivos de la historia oficial. Ospina sugiere que se deben buscar los testimonios que narren las tramas del pueblo colombiano, se trata de reconstruir momentos que, aunque oscuros y dolorosos, permiten reconocer luchas, esperanzas y frustraciones de diferentes sectores de la sociedad.

Acudiendo de nuevo a Cien años de soledad, Ospina advierte el peligro de padecer la peste del olvido que sufrió Macondo. Es un deber no olvidar las voces de los marginados socialmente, de las víctimas de la violencia, pero también de aquellas personas que desde el anonimato, desde la periferia social, desde el arte han creado diversidad de manifestaciones culturales, narrando sus vidas o reinventándolas.

En la misma línea Martín Barbero (2005) plantea la urgencia de construir una nueva narración que dé cuenta del devenir de los pueblos de Colombia. Al respecto escribe:

Nuestro país se halla especialmente necesitado -como certeramente ha observado D. Pécaut- más que de un mito fundador, de un relato nacional en el que se entretejan las memorias de sus regiones y sus etnias, de sus mujeres y sus nuevas generaciones. Y en el que se refunde y reinvente el país (párr. 10).

Se trata de una reinvención de la nación que dé espesura a una memoria colectiva que posibilite imaginar y comprender las peripecias de múltiples actores sociales, principio básico para llevar a cabo auténticas políticas de reco- 
nocimiento que no satanicen a los "extraños" y den voz a los "diferentes".

\section{Notas}

1 Sobre el sentido de lo que es una nación se puede encontrar una amplia literatura, lo que impide aproximarse a una definición única, sin embargo, en términos de Gallie (1998) se trata de un concepto esencialmente impugnado: "cuando examinamos los diferentes usos de estos términos y los argumentos característicos en los que figuran, pronto advertimos que no hay un solo uso general, claramente definible, de ninguno de ellos que pueda establecerse como el uso estándar o correcto" (p. 6). No obstante, la interpretación de estos conceptos y la aclaración del modo en que se decide emplearlos resulta primordial para orientar la vida en comunidad.

2 Tzvetan Todorov (2007) denuncia la inexistencia de principios humanistas de tal proyecto político, puesto que desde un enfoque "interno" la nación se crea en oposición sangrienta a los privilegios estatutarios defendidos por un rey y su nobleza; mientras que desde un enfoque "externo" la nación se crea desde las reivindicaciones de un grupo político respecto a otro. De modo que esta idea entraña "una elección preferencial del país de uno contra los demás países; una elección y, en consecuencia, un acto antiuniversalista" (p. 204).

3 Para Martín Barbero (2003) el ideal romántico de nación le otorgó gran importancia al pueblo, a sus mitos y tradiciones, pero al presentarlo como un "alma", como una "esencia espiritual”, lo despojó de su realidad histórica concreta, de sus conflictos y transformaciones sociales; de manera que a su cultura la dotó de un aura de misticismo, la colocó en un pasado remoto y ajeno a las dinámicas del presente, así que, al igual que los ilustrados, los románticos centraron la idea de nación en principios abstractos que el Estado debía custodiar. "Los románticos acaban así encontrándose de acuer- do con sus adversarios, los ilustrados: ¡culturalmente hablando el pueblo es el pasado! No en el mismo sentido, pero sí en un buen trecho. Para ambos el futuro lo configuran las generalidades, esas abstracciones en las que se encarna, 'realizándolas', la burguesía: Un Estado que reabsorbe desde el centro todas las diferencias culturales, ya que resultan obstáculos al ejercicio unificado del poder, y una Nación no analizable en categorías sociales, no divisible en clases, ya que se halla constituida por lazos de naturales, de tierra y de sangre" (p. 11).

4 Para Todorov (2007) la síntesis que plantea Renan entre algunos principios ilustrados y románticos resulta bastante compleja, ya que "la coexistencia de estos dos 'criterios' evidentemente crea problemas. Si el hombre no se improvisa, si está determinado por su pasado, si son los ancestros quienes se expresan en él, ¿acaso aún puede hablarse de su ingreso a la nación como una adhesión libre, como un ejercicio de la voluntad? Si son los ancestros quienes nos han hecho lo que somos, ¿acaso se nos puede hacer aún responsables de nuestros actos, se nos pueden hacer exigencias morales?" (p. 261).

5 En este punto resulta útil recordar que para Norberto Bobbio (2003) el Estado moderno se define a partir de tres rasgos que lo erigen en la institución política por antonomasia que tiene por fin mínimo garantizar el orden y la seguridad: a) exclusividad, solo el Estado posee el dominio de la fuerza física; b) universalidad, las decisiones del Estado son legítimas, válidas para todos; y c) inclusividad, con ciertos límites (por ejemplo el respeto a los derechos individuales) el Estado puede intervenir en diferentes ámbitos de la sociedad (p. 182).

${ }^{6}$ Después del auge de los totalitarismos, diversos autores entendieron la nación como un artificio del Estado y no como el resultado de esencias perennes o realidades sociales objetivas. Para Hobsbawm (2002) la nación es una creación del liberalismo moderno, el cual, pese 
a su novedad y a sus apuestas universalistas, requiere de un proceso de ingeniería social para inventar tradiciones que permitan darle continuidad y estabilidad al proyecto estatal naciente, "las naciones modernas y todo lo que las rodea reclaman generalmente ser lo contrario de la novedad, es decir, buscan estar enraizadas en la antigüedad más remota, y ser lo contrario de lo construido, es decir, buscan ser comunidades humanas tan naturales que no necesiten más definición que la propia autoafirmación" (pp. 20-21). En la misma línea Gellner (1998) sostiene que la nación es el producto de una voluntad política, la cual se encuentra ligada a un fuerte proyecto cultural hegemónico dirigido por el Estado, "el nacionalismo engendra las naciones, no a la inversa. No puede negarse que aprovecha -si bien de forma muy selectiva, y a menudo transformándolas radicalmente- la multiplicidad de culturas, o la riqueza cultural preexistente, heredada históricamente [...]. El engaño y autoengaño básico que lleva a cabo el nacionalismo consisten en lo siguiente: el nacionalismo es esencialmente la imposición general de una cultura desarrollada a una sociedad en que hasta entonces la mayoría, y en algunos casos la totalidad, de la población se había regido por culturas primarias. Esto implica la difusión generalizada de un idioma mediatizado por la escuela y supervisado académicamente, codificado según las exigencias de una comunicación burocrática y tecnológica módicamente precisa" (pp. 81-82). Por último, para Benedict Anderson (1993) la nación es imaginada porque "aun los miembros de la nación más pequeña no conocerán jamás a la mayoría de sus compatriotas, no los verán, ni oirán siquiera hablar de ellos, pero en la mente de cada uno vive la imagen de su comunión" (p. 23). Y esta imagen se configura gracias al lenguaje, a narrativas diversas que posibilitan la identificación de un grupo humano como un "nosotros". Así que, para los autores mencionados, la existencia de la nación se liga a un proyecto político voluntarista que necesita difundir, crear u olvidar ciertas tradiciones culturales para que un proyecto estatal perviva.
7 Vattimo (1994) habla del auge de la posmodernidad a partir de la lectura de dos fenómenos sociales, primero, "la desaparición de la historia como entidad unitaria", segundo, "la irrupción de la sociedad de la comunicación". Ambos acontecimientos traen consigo la desaparición de los grandes metarrelatos y la afirmación del perspectivismo, el cual da lugar al reconocimiento de diversas formas de emancipación del hombre: "El efecto emancipante de la liberación de las racionalidades locales no es, sin embargo, solamente garantizar a cada uno la posibilidad más completa de reconocimiento y de 'autenticidad'; como si la emancipación consistiese en manifestar finalmente lo que cada uno es de verdad (en términos metafísicos, spinozianos): negro, mujer, homosexual, protestante, etc. La causa emancipante de la liberación de las diferencias y de los 'dialectos' consiste más bien en el compendioso efecto de desarraigo que acompaña al primer efecto de identificación. Si, en fin de cuentas, hablo mi dialecto en un mundo de dialectos, seré también consciente de que no es la única lengua, sino cabalmente un dialecto más entre muchos. Si profeso mi sistema de valores -religiosos, estéticos, políticos, étnicos- en este mundo de culturas plurales, tendré también una conciencia aguda de la historicidad, contingencia, limitación de todos estos sistemas, comenzando por el mío" (p. 18).

8 Smith (2003) asegura que un enfoque nacionalista posmoderno es crítico de posturas esencialistas que conciben la nación como realidad cultural perenne o como artefacto dirigido y controlado por los intereses del capitalismo, en lugar de ello, desde esta perspectiva se propone que la nación se crea o interpreta desde una pluralidad de representaciones culturales, así que "esta lectura esencialmente posmodernista convierte la nación en un relato que recitar, un discurso que interpretar y un texto que deconstruir" (p. 13). Si bien el autor muestra algunas reservas frente a dicha concepción, ya que en ella se corre el riesgo de reducir la nación a meros procesos de ficción, está de acuerdo en revisar enfoques tradicionales, de modo 
que propone concebir a los estudiosos del nacionalismo como "arqueólogos políticos que redescubren y reinterpretan el pasado comunitario" (p. 33). Smith reconoce que la nación es un artefacto, pero este no es arbitrario, se basa en la reinterpretación constante del patrimonio cultural de un pueblo y en la la emotividad que evocan sus tradiciones y sus símbolos, pues en ellos se encuentran vías legítimas para proyectar la identidad nacional.

9 Sobre este tema puede revisarse los trabajos de María Teresa Uribe y Liliana María López, 2006; 2008.

\section{Referencias}

Anderson, B.(1993). Comunidades imaginadas: reflexiones sobre el origen y la difusión del nacionalismo. México: Fondo de la cultura económica.

Arendt, H. (1974). Los orígenes del totalitarismo. Barcelona: Tauros.

Arendt, H. (1993). La Condición Humana. Barcelona: Paidós.

Bobbio, N. (2003). Teoría general de la política. Madrid: Trotta.

Cruz-Prados, A. (2005). El Nacionalismo. Una ideología. Madrid: Tecnos.

Ficthe, J. G. (1994). Discursos a la nación alemana. Barcelona: Altaya.

Gallie, W. B. (1998). Conceptos esencialmente impugnados. México: Universidad Autónoma de México.

García-Canclini, N. (1989). Culturas híbridas. Estrategias para entrar y salir de la modernidad. México: Editorial Grijalbo.

García-Canclini, N. (2003). Noticias recientes sobre la hibridación. Revista transcultural de música, 7. Recuperado de http://www. redalyc.org/articulo.oa?id $=82200702$

Gellner, E. (1988). Naciones y nacionalismo. Madrid: Alianza Editorial.

Herder, J. (2000). Genio nacional y medio ambiente. En A. Fernández (Comp.), $L a$ invención de la nación. Lecturas de la identidad de Herder a Homi Bhabha (pp. 27-52). Buenos Aires: Manantial.

Hobsbawm, E. (2000). Naciones y nacionalismos. Barcelona: Crítica.

Hobsbawm, E. (2002). La invención de la tradición. Barcelona: Crítica.

Martín-Barbero, J. (2003). De los medios a las mediaciones. Comunicación, cultura y hegemonía. Bogotá: Convenio Andrés Bello.

Martín-Barbero, J.(2005). Paul Ricoeur, Memoria y promesa. Pidepágina, 4. Recuperado de http://www.filosofiayliteratura.org/Lin daraja/ricoeur/martinbarbero.htm

Ospina, W. (2001). Colombia en el planeta. Relato de un país que perdió la confianza. Recuperado de http://fresno.org.co/150/ documentos/Colombiaenelplaneta.pdf

Renan, E. (2000). ¿Qué es una nación?. En A. Fernández (Comp.), La invención de la nación. Lecturas de la identidad de Herder a Homi Bhabha (pp. 53-66). Buenos Aires: Manantial.

Smith, E. (2003). ¿Gastronomía o genealogía? El papel del nacionalismo en la reconstrucción de las naciones. En A. Smith \& R. Máiz (Eds.), Nacionalismos y movilización política (pp. 7-40). Buenos Aires: Prometeo libros.

Todorov, T. (1989). Nosotros y los otros. México: Siglo XXI editores. 
Uribe, M. T. (2001). Nación, ciudadano y soberano. Medellín: Corporación región.

Uribe, M. T., \& López, L. M(2006). Las palabras de la guerra. Un estudio sobre las guerras civiles en Colombia. Medellín: Instituto de Estudios Políticos, Universidad de Antioquia; La carreta editores.

Uribe, M. T., \& López, L. M (2008). La guerra por las soberanias. Memorias y relatos en la guerra civil de 1859-1862 en
Colombia. Medellín: Instituto de Estudios Políticos, Universidad de Antioquia; La carreta editores.

Vásquez, J. (1973). Memoria perfeccionada. Recuperado de http://www.enriquevila matas.com/escritores/escrvasquezjg1.html

Vattimo, G. (Ed.) (1994). Posmodernidad: “¿una sociedad transparente?”. En, En torno a la posmodernidad (pp. 9-18). Bogotá: Anthropos. 